\title{
Fighting the Cause of Alzheimer's and GNE Myopathy
}

\author{
Shreedarshanee Devi, Rashmi Yadav, Pratibha Chanana and Ranjana Arya* \\ School of Biotechnology, Jawaharlal Nehru University, New Delhi, India
}

Age is the common risk factor for both neurodegenerative and neuromuscular diseases. Alzheimer disease (AD), a neurodegenerative disorder, causes dementia with age progression while GNE myopathy (GNEM), a neuromuscular disorder, causes muscle degeneration and loss of muscle motor movement with age. Individuals with mutations in presenilin or amyloid precursor protein (APP) gene develop AD while mutations in GNE (UDP $N$-acetylglucosamine 2 epimerase/ $N$-acetyl Mannosamine kinase), key sialic acid biosynthesis enzyme, cause GNEM. Although GNEM is characterized with degeneration of muscle cells, it is shown to have similar disease hallmarks like aggregation of $A \beta$ and accumulation of phosphorylated tau and other misfolded proteins in muscle cell similar to AD. Similar impairment in cellular functions have been reported in both disorders such as disruption of cytoskeletal network, changes in glycosylation pattern, mitochondrial dysfunction, oxidative stress, upregulation of chaperones, unfolded

Edited by:

Mohammad Amjad Kamal, King Abdulaziz University,

Saudi Arabia

Reviewed by:

Petr A. Slominsky, Institute of Molecular Genetics (RAS), Russia

Chaoyang Li, Wuhan Institute of Virology (CAS),

China

*Correspondence:

Ranjana Arya

arya.ranjana24@gmail.com; ranjanaa@jnu.ac.in

Specialty section: This article was submitted to

Neurodegeneration,

a section of the journal

Frontiers in Neuroscience

Received: 28 February 2018 Accepted: 06 September 2018

Published: 15 October 2018

Citation:

Devi S, Yadav R, Chanana P and Arya $R$ (2018) Fighting the Cause of Alzheimer's and GNE Myopathy.

Front. Neurosci. 12:669.

doi: 10.3389/fnins.2018.00669 protein response in ER, autophagic vacuoles, cell death, and apoptosis. Interestingly, $\mathrm{AD}$ and GNEM are the two diseases with similar phenotypic condition affecting neuron and muscle, respectively, resulting in entirely different pathology. This review represents a comparative outlook of AD and GNEM that could lead to target common mechanism to find a plausible therapeutic for both the diseases.

Keywords: amyloid $\beta$, NFT, GNE, hyposialylation, sialic acid, ER stress, apoptosis, autophagy

\section{INTRODUCTION}

Aging is the process, which initiates with subclinical changes at molecular level including accumulation of mutations, telomere attrition, epigenetic alterations resulting in genome instability (López-Otín et al., 2013). These changes multiply at a very fast rate, ultimately leading to the morphological and functional deterioration of brain by progressive loss of the neurons, reduction in the levels of neurotransmitters at the synaptic junction and disruption of integrity of the brain (Sibille, 2013). In addition to neurons, muscle cells are also affected with age. Loss of muscle mass, reduction in muscle fiber size and number is observed in muscles with age that decreases muscle strength (Narici and Maffulli, 2010; Siparsky et al., 2014). Thus, age is a common risk factor for both neurodegenerative and neuromuscular diseases, that progress with time.

The neurodegenerative disorders like Alzheimer's disease (AD), Parkinson's disease, Huntington's disease and amyotrophic lateral sclerosis (ALS) share similar pattern of brain alterations and relate to each other at sub-cellular levels in numerous studies (Garden and La Spada, 2012; Montie and Durcan, 2013). Oxidative stress and altered $\mathrm{Ca}^{2+}$ and mitochondrial

Abbreviations: $A \beta, \beta$ amyloid; AD, Alzheimer's disease; GNE, UDP-GlcNAc 2-epimerase/ManNAc kinase; GNEM, GNE myopathy; NFT, neurofibrillary tangles. 
dysfunctions cause neuronal damage with age (Thibault et al., 1998, 2001). Further, neurons do not divide (with rare exceptions), thus cellular damage tend to accumulate with age (Sibille, 2013). Similarly neuromuscular disorders such as multiple sclerosis, muscular dystrophy, GNE related myopathy, Myasthenia gravis, Spinal muscular atrophy and ALS show subcellular damage in muscle cells where oxidative stress and altered calcium/mitochondrial, and ER stress are observed (Kanekura et al., 2009; Roussel et al., 2013; Stone and Lin, 2015; Xiang et al., 2017). Muscle cells are also among the least dividing cells with average lifespan of 15 years or sometimes reaching four decades. Due to its long life span like neurons, the cellular damage in muscle also accumulates in due course of time. As the age progresses, the satellite cells of muscle decline reducing the regeneration capacity of healthy muscle in place of affected cells (Narici and Maffulli, 2010). Whether there is any correlation of cellular damage in neurons versus muscle cells that can be a common therapeutic target is not known.

Indeed some disorders such as ALS can be placed in either of the two disorders as it affects both neurons and muscle cells. Several neuromuscular disorders, which include muscular dystrophies have reported degeneration of neurons in brain and affect the cognitive function leading to memory loss (Anderson et al., 2002; Ricotti et al., 2011). In ALS, loss of motor neurons affect the movement of various muscles of body leading to muscle wasting and paralysis, along with cognitive impairment (Taylor et al., 2016). Interestingly, a novel missense mutation (histidine to arginine at 705 amino acid) in GNE gene (UDP $N$-acetylglucosamine 2 epimerase/ $N$ acetyl Mannosamine kinase) was observed in familial ALS patient (Köroğlu et al., 2017). Mutation in GNE gene causes GNEM, a rare neuromuscular disorder with completely different pathology compared to ALS (Huizing and Krasnewich, 2009). This raises a possibility of a missing link between the two disorders where the pathomechanisms might merge at a common target.

In this review, we have correlated and compared Alzheimer's disease, a neurodegenerative disorder with GNEM, a neuromuscular disorder and put forth how these diseases share common pathological events like aggregation of misfolded proteins, oxidative stress, mitochondrial dysfunction, autophagy and cellular death. This will help us to find a common therapeutic approach for the treatment of these diseases.

\section{EPIDEMIOLOGY}

Among various neurological disorders, Alzheimer's disease is the most common form of dementia accounting for $60-80 \%$ of all the cases of dementia, with worldwide prevalence above 45 million $^{1}$. It is more prevalent in the Western European and North American population. On the other hand, GNEM is a rare genetic neuromuscular disorder with worldwide prevalence of 1-9 in a millionth population $\left(\right.$ Orphanet $\left.^{2}\right)$. GNEM has been

${ }^{1}$ www.alzheimers.net

${ }^{2}$ http://www.orpha.net/ reported in the Irish, Jewish, Japanese and Indian populations. Also, there are reports of GNEM from North America, European (United Kingdom and Scotland) and other Asian country like Thailand (Bhattacharya et al., 2018).

\section{CAUSES, CHARACTERISTICS AND GENETIC PREDISPOSITION}

$\mathrm{AD}$ is a multifactorial disease without any single cause. The main characteristic features of $\mathrm{AD}$ are senile plaques, composed mainly of extracellular amyloid- $\beta$ (A $\beta$ ) peptides, and Neurofibrillary Tangles (NFTs) formed after accumulation of intracellular hyperphosphorylated tau (Serrano-Pozo et al., 2011). GNEM is caused by autosomal recessive mutation in GNE gene responsible for sialic acid biosynthesis. The characteristic features for GNEM involves weakness in the distal muscles, sparing the quadriceps, presence of rimmed vacuoles in muscle fibers and tubulofilamentous inclusions of aggregated proteins such as $A \beta$ and phosphorylated tau (Jay et al., 2009). Despite the differences in tissues that are affected in the two diseases, accumulation of aggregates of amyloid- $\beta$ and tau are common characteristics of both the diseases.

Initial symptom of $\mathrm{AD}$ is gradual loss in ability of the person to remember new information (Souchay and Moulin, 2009). The greatest risk factor for the development of $\mathrm{AD}$ is age as its pathological features increase exponentially with age (doubling every 5 years after the attainment of 65 years of age) (Querfurth and LaFerla, 2010). In GNEM, the initial symptoms include foot drop and weakness in the distal muscles, which gradually worsen with age toward wheel-chair dependence of patients. In GNEM, unlike AD, the brain function has been reported as normal (Anada et al., 2014). The onset of AD is late adulthood while GNEM onset is early adulthood during the second or third decade of life. How aging leads to sudden onset of GNEM is not known.

Beside aging, $\mathrm{AD}$ is caused due to mutation in either the presenilin genes or in Amyloid Precursor Protein (APP) gene (Goate et al., 1991; Hutton and Hardy, 1997; Holtzman et al., 2011). There is also an increased risk of $\mathrm{AD}$ in individuals suffering from Down's syndrome because chromosome 21 includes a gene encoding the production of APP (Wiseman et al., 2015). The epsilon four allele of the apolipoprotein $\mathrm{E}$ gene (APOE) located on chromosome 19 is found to be a risk factor for AD (Reiman et al., 2005). People with a history of diabetes, hypertension, obesity, smoking, head injury leading to memory loss and a family history of $\mathrm{AD}$ in close relatives are at a greater risk of $\mathrm{AD}$ (Barnes and Yaffe, 2011). The prevalence of $\mathrm{AD}$ is higher in women and less educated masses (Letenneur et al., 2000).

On the other hand, GNEM is caused due to mutation in GNE (UDP-GlcNAc 2-epimerase/ManNAc kinase) gene that catalyzes the first two rate limiting steps in the biosynthesis of sialic acid (Jay et al., 2009). Whether hyposialylation is the only cause of GNEM is still unknown. GNEM is a genetic disorder and not known to be associated with lifestyle disease. No gender bias has been reported for GNEM. A complete comparison of 
characteristics of both AD and GNEM has been described in Table 1.

\section{DISEASE PATHOLOGY}

In normal condition, neuronal cells release soluble $\mathrm{A} \beta$ after cleavage of a cell surface receptor called APP. In case of AD, the cleavage is abnormal leading to the precipitation of $A \beta$ into dense beta sheets and formation of senile plaques (Zhang et al., 2011). To clear the amyloid aggregates, an inflammatory response is generated by astrocytes and microglia leading to the destruction of adjacent neurons and their neuritis (Norfray and Provenzale, 2004; Querfurth and LaFerla, 2010).

The tau protein is a microtubule stabilizing protein and has a role in intracellular transport (both axonal and vesicular). In its abnormally hyper-phosphorylated form, tau form intracellular aggregates called the NFTs or senile plaques, interfering with normal axonal transport of molecules along microtubules (Norfray and Provenzale, 2004).

In GNEM, main pathological feature includes formation of rimmed vacuoles, which is comprised of aggregated proteins such as $A \beta$ and tau (Nalini et al., 2010). Cytoplasmic and nuclear inclusion bodies have also been observed by electron microscopy in muscle biopsies, which contain degradative products from the membrane, cytoplasmic tubulofilaments and mitochondria with irregular size and shape (Huizing and Krasnewich, 2009). However, since GNE is a key sialic acid biosynthetic enzyme, mutation in GNE affects the sialylation of proteins (Noguchi et al., 2004). The immunohistochemistry of GNEM muscle samples revealed upregulation of $\alpha \beta$-crystallin,
NCAM, MHC-1, and iNOS levels (Fischer et al., 2013). NCAM was hyposialylated in GNEM and proposed as diagnostic marker for GNEM (Ricci et al., 2006). In aging brain and $\mathrm{AD}$, the expression and function of NCAM and MHC-1 was altered that may result in synaptic and cognitive loss (Aisa et al., 2010). Also, reduced polysialated-NCAM load was reported in entorhinal cortex causing AD (Murray et al., 2016). Thus, NCAM sialylation can be a common target in the pathology of $\mathrm{AD}$ and GNEM in addition to $\mathrm{A} \beta$ and tau accumulation.

\section{DIAGNOSIS}

Medical and family history of individuals, which include psychiatric history, changes in behavior and cognitive functions, help in the diagnosis of AD. Amyloid plaques, presence of NFT's and distribution in the brain are used to establish the disease by an autopsy based pathological evaluation. The clinical diagnosis of $\mathrm{AD}$ is about $70-90 \%$ accurate relative to the pathological diagnosis (Beach et al., 2012).

GNEM is clinically characterized by weakness in tibialis anterior muscles with a unique sparing of the quadriceps leading to foot drop, gait abnormalities, mild or no elevation in serum creatine kinase levels with no involvement of cardiac muscles, usually in the second or third decade of life (Nalini et al., 2013). Pathologically, GNEM is characterized by presence of rimmed vacuoles in muscle biopsies, without inflammation (Argov and Yarom, 1984). The confirmation of GNEM mainly relies on identification of bi-allelic mutation in GNE gene. As more than 190 mutations in GNE have been identified worldwide, complete

TABLE 1 | Comparison of the characteristics of AD and GNEM.

\begin{tabular}{|c|c|c|}
\hline & \multicolumn{2}{|c|}{ Characteristics of AD and GNEM } \\
\hline & AD & GNEM \\
\hline Disease type & Neurodegenerative & Neuromuscular \\
\hline Onset of the disease & Early (5\%) and late onset (>95\%) & Early adulthood \\
\hline Age & Mainly above 65 years of age & 20-30 years of age \\
\hline Prevalence & 45 Million and above & $\sim 1-9$ in one Million \\
\hline Demographics & $\begin{array}{l}\text { Worldwide but common in Western Europe and North American } \\
\text { population }\end{array}$ & Jewish, Japanese and Indian population \\
\hline Initial signs & Loss in memory & Foot drop \\
\hline Gender biasness & Higher in women & Not found \\
\hline Mutation & FAD-autosomally dominant & Autosomal recessive \\
\hline Genetic defects & Mutations in Presenilin genes, APOE gene & Mutations in GNE gene \\
\hline Symptoms & Memory loss, agitation, sleeplessness, and delusions & Foot drop, weakness in distal muscles, and difficulty in walking \\
\hline Progressiveness & Fast & Slow \\
\hline Brain function & Affected & Not affected \\
\hline Pathological effect & $\begin{array}{l}\text { Damage to limbic system and neocortical region, Senile plaques } \\
\text { and NFTs, aggregation of proteins }\end{array}$ & $\begin{array}{l}\text { Rimmed vacuole of aggregated proteins tubulofilaments and small } \\
\text { fibers, cytoplasmic and nuclear inclusion bodies, aggregation of } \\
\text { proteins }\end{array}$ \\
\hline Diagnosis & $\begin{array}{l}\text { Medical history, pathological diagnosis of plaques and NFTs, MRI } \\
\text { and CT scan of brain lesions, levels of serum B12, TSH, T4 etc. }\end{array}$ & $\begin{array}{l}\text { Time of disease onset, Gait study, walking pattern, pathological } \\
\text { study of rimmed vacuoles and other factors, biallelic mutations in } \\
\text { GNE gene through sequencing }\end{array}$ \\
\hline Treatment & $\begin{array}{l}\text { Acetylcholinesterase (Ach esterase) inhibitors, drugs targeting } A \beta \\
\text { and tau protein accumulation }\end{array}$ & $\begin{array}{l}\text { Supplementation with sialic acid and its precursor molecules, IVIG } \\
\text { administration, gene therapy }\end{array}$ \\
\hline
\end{tabular}


sequencing of the GNE is necessary for diagnosis of GNE myopathy.

\section{COMPARATIVE ANALYSIS OF MOLECULAR MECHANISMS AFFECTING AD AND GNEM}

\section{Effect of Glycosylation, Particularly Sialylation, in AD and GNEM}

Glycosylation is the process of incorporation of glycan, either monosaccharides or oligosaccharides, unit to proteins and lipid moieties (Spiro, 2002). The role of glycosylation in case of $\mathrm{AD}$ was first reported when impaired glucose metabolism increased toxicity from $\mathrm{A} \beta$ and affected glycosylation pattern (Ott et al., 1999; Peila et al., 2002; Chornenkyy et al., 2018). Several key proteins involved in $A \beta$ deposition cascade such as APP, BACE-1 ( $\beta$ secretase), $\gamma$-secretase, nicastrin, neprisilin (NEP) undergo altered glycosylation in AD (Kizuka et al., 2017). Deletion of N-glycosylation of APP protein results in its reduced secretion (Schedin-Weiss et al., 2014). APP trafficking from trans-Golgi network to plasma membrane and non-amyloidogenic processing is enhanced by O-GlcNAcylation of APP (Chun et al., 2015). Interestingly, enhanced sialylation of APP increased APP secretion and $\mathrm{A} \beta$ production (Nakagawa et al., 2006). Defect in sialic acid biosynthesis due to mutation in GNE affects sialylation of glycoproteins in GNEM. Several proteins such as neural cell adhesion molecule (NCAM), $\alpha$-dystroglycan, integrin, IGF-1R, and other proteins have been found with altered sialylation in absence of functional GNE (Huizing et al., 2004; Ricci et al., 2006; Grover and Arya, 2014; Singh et al., 2018). However, changes in glycosylation pattern of APP or A $\beta$ are not studied in GNEM despite elevated levels of APP reported in ALS and GNEM (Koistinen et al., 2006; Fischer et al., 2013). Thus, there is a need to investigate whether hyposialylation of muscle cells, as effect of mutation in GNE, affects the glycosylation pattern and sialylation of accumulated glycoproteins and proteins like $\mathrm{A} \beta$, presenilin-1 etc.

Proper glycosylation of nicastrin (a subunit of $\gamma$-secretase) affects its trafficking to Golgi apparatus and proper binding to presenilin-1, thereby, inhibiting APP processing and $\gamma$-secretase substrate preference (Yang et al., 2002; Xie et al., 2014; Moniruzzaman et al., 2018). Expression of glycosylated NEP, protein involved in $\mathrm{A} \beta$ clearance, is also reduced in $\mathrm{AD}$ (Reilly, 2001). Interestingly, in GNEM also, the glycosylation and sialylation of neprilysin is dramatically reduced, affecting its expression and normal enzymatic activity (Broccolini et al., 2008). The effect of reduced activity in NEP in GNEM may lead to its failure of clearance of $A \beta$ from muscle. Additionally, it has also been reported that enzyme GNE undergoes O-GlcNAcylation thereby, modulating its enzymatic activity (Bennmann et al., 2016). Thus, it would be of interest to study effect of altered sialylation due to GNE mutation on glycosylation pattern of aggregating proteins.
Several reports indicate alteration of protein sialylation to be a leading cause of AD (Wang, 2009; Schnaar et al., 2014). Binding of $A \beta$ to cells is sialic acid dependent as its binding to surface is mediated through sialylated gangliosides, glycolipids, and glycoproteins (Ariga et al., 2001). The levels of sialyltransferase reduce with age that may contribute to altered sialic acid levels (Maguire et al., 1994; Maguire and Breen, 1995). In addition, clearance of $A \beta$ by microglia is enhanced in absence of sialylated immunoglobulin, CD33 (siglec-33) (Jiang et al., 2014; Siddiqui et al., 2017). This suggests that sialylation is important for $A \beta$ uptake and accumulation.

Interestingly, altered levels of sialyltransferases ST3Gal5 and ST8Sia1 were reported in HEKAD293 cells overexpressing wild type recombinant GNE resulting in increased levels of gangliosides GM3 and GD3 (Wang et al., 2006). Thus, GNE may affect sialyltransferases with an unknown mechanism. Molecules affecting sialyltransferase levels may influence $A \beta$ uptake in both GNEM as well as AD. Thus, changes in the sialylation pattern of $\mathrm{A} \beta$ deposition cascade proteins in muscle cells may affect rimmed vacuole formation in GNEM and offer new therapeutic approach.

\section{Role of Cytoskeleton Network in AD and GNEM}

Cytoskeletal proteins are important functional proteins in both neuronal and muscle cells. In muscle, they help in conducting contraction and movement, while in neurons, they have a vital role in neuronal plasticity that is important for learning and memory process. Cytoskeletal proteins include different proteins like actin, tubulin, and lamin that provide mechanical support to the cell and modulate their dynamics inside the cell.

Tau, the first microtubule associated protein to be identified, was found to be one of the important hallmarks of $\mathrm{AD}$ along with $A \beta$. Tau directly helps in self-assembly of microtubule from tubulin. In $\mathrm{AD}$, tau is found to be hyperphosphorylated at different site than normal (Gong et al., 2005; Hanger et al., 2007). The extent of tau aggregation is correlated with amount of phosphorylation at different sites (Iqbal et al., 2008). Also increased auto-antibodies of tubulin and tau were found in the serum of $\mathrm{AD}$ patients indicating a robust target for disease diagnosis (Salama et al., 2018). In GNEM, phosphorylated tau has been observed to accumulate in rimmed vacuoles (Nogalska et al., 2015), but whether aggregated tau is hyperphosphorylated from the normal form is not yet studied.

Actin dynamics and modulation of G-actin and F-actin is an important feature for neuronal plasticity and memory developments (Penzes and Rafalovich, 2012). Impaired cognitive function has been reported in $\mathrm{AD}$ pathology where cofilin-1, an actin depolymerizer, was found to be inactive (Barone et al., 2014). Inactivation of cofilin 1 contributes to actin dependent impairment of synaptic plasticity and thus, learning (Rust, 2015). Further, cofilin- 1 inactivation is $\gamma$-secretase dependent, which controls $\mathrm{A} \beta$ peptide production. Also, cofilin-actin rods result in synaptic loss in AD (Bamburg et al., 2010). Small GTPases like RhoA, Rac1, and Cdc42 regulate APP, formation of $A \beta$ and neurotoxicity (Boo et al., 2008; Wang et al., 2009). Phosphorylation of collapsin mediator response 
protein-2 (CRMP-2) in AD disrupts its binding with kinesin hampering axonal transport and resulting in neuronal defect (Mokhtar et al., 2018). RhoGTPases also play important role in muscle differentiation and muscle contraction (DeHart and Jones, 2004; Zhang et al., 2012). Interestingly, GNE has been shown to interact with CRMP-1, $\alpha$-actinin-1, and $\alpha$-actinin-2, key cytoskeletal regulatory proteins (Weidemann et al., 2006; Amsili et al., 2008; Harazi et al., 2017). Being an actin binding protein, binding of $\alpha$-actinin- 1 and $\alpha$-actinin- 2 with GNE raises a possibility of impaired actin function in GNEM. Differential cytoskeletal protein expression was observed in muscle biopsy samples of GNEM patients (Sela et al., 2011). Upstream of actin, FAK (focal adhesion complex) and integrin (extracellular matrix protein) function was affected in mutant GNE cells (Grover and Arya, 2014). It has also been reported that induction of $A \beta$ led to the increased expression of FAK and autophosphorylation at Tyr397 (Han et al., 2013). However, role of RhoA, actin, cofilin needs to be further elucidated in GNEM. Taken together these studies indicate cytoskeletal proteins to be a common target that regulate $A \beta$ production and need therapeutic intervention to explore effective molecules.

\section{Mitochondrial Dysfunction in AD and GNEM}

Mitochondria are self-dividing organelles undergoing fission and fusion inside a cell. It is the power house of a cell that provides energy by oxidative phosphorylation during TCA cycle. Neurons and muscle cells have higher demand for mitochondria for their neuronal processes and muscle contraction, respectively. It has been reported that different cytoskeletal proteins help in motility of mitochondria in the cytoplasm (Lackner, 2013). Accumulation of $A \beta$ and increased cellular death has been reported upon dissection of brains of AD patients (Cha et al., 2012). Further, $\mathrm{A} \beta$ accumulation in mitochondria precedes amyloid plaque, indicative of an early stage AD (Ankarcrona et al., 2010). In the early stages of $\mathrm{AD}$, the number of mitochondria in the affected neurons is highly reduced leading to decreased glucose metabolism and impaired TCA cycle enzyme activity (Bubber et al., 2005; Mosconi, 2005). Additionally, elevated level of oxidative damage and significant increase in mutation of mtDNA and cytochrome $c$ oxidase has been reported in $\mathrm{AD}$ patients (Castellani et al., 2002). Further, impaired mitochondrial trafficking has been observed in rat hippocampal neurons upon exposure to sub-cytotoxic levels of $\mathrm{A} \beta$ (Rui et al., 2006). Altered calcium homeostasis affects ATP generation and cause mitochondrial dysfunction (Supnet and Bezprozvanny, 2010; Swerdlow, 2018).

In GNEM, upregulation of a number of mitochondrial genes and transcript encoding mitochondrial proteins like COX, Cytochrome C Oxidase, ATPases, NADH dehydrogenase etc., have been reported in GNEM patient muscle biopsies (Eisenberg et al., 2008). Vacuolar and swollen mitochondria indicative of structure and functional dysfunction have been observed in HEK cells with mutated GNE (Eisenberg et al., 2008). Since function of mitochondria is dependent on its structure, increased branching of mitochondria observed in cells of GNEM patients could lead to oxidative stress (Eisenberg et al., 2008). Thus, both GNEM and AD show mitochondrial dysfunction. It would be of interest to determine the stage at which mitochondria are affected in GNEM and whether any A $\beta$ accumulation occurs in mitochondria besides rimmed vacuoles.

In $\mathrm{AD}$ mouse study, COX gene knock out reduced oxidative stress by reducing $A \beta$ plaque formation (Fukui et al., 2007). Inhibition of COX 2 function results in protection of neurons and reduces the accumulation of $\mathrm{A} \beta$ in neurons of $\mathrm{AD}$ transgenic mice (Woodling et al., 2016). In GNEM, COX7A protein is reported to be upregulated (Eisenberg et al., 2008). Thus, inhibiting COX gene in GNEM may reduce mitochondrial oxidative stress and inhibit $\mathrm{A} \beta$ aggregate formation in GNE deficient cells and could serve as an important therapeutic target.

\section{Effect of Oxidative Stress in AD and GNEM}

Oxidative stress is a key player in many neurodegenerative diseases. With age, oxidative stress in brain elevates due to imbalance of redox potential leading to generation of reactive oxygen species (ROS) (Andreyev et al., 2005; Wang and Michaelis, 2010). When the amount of ROS species produced is greater than scavenged by ROS defense mechanisms, it leads to oxidative stress leading to cell damage (Feng and Wang, 2012). Reports suggest that $A \beta(1-42)$ accumulation is associated with oxidative stress in hippocampal neuron of C. elegans (Yatin et al., 1999). Phosphorylation of tau is also reported to be increased during oxidative stress via activation of glycogen synthase kinase 3- $\beta$ (Lovell et al., 2004). Aberrant S-nitrosylation of proteins at cysteine residue of ApoE, Cdk5, and PDI leads to oxidative stress and neurodestruction (Zhao et al., 2014). In fact, oxidation of proteins in neurons that control $\mathrm{A} \beta$ solubilization and tau hyperphosphorylation severely affect progression of $\mathrm{AD}$.

In GNEM, upregulation of cell stress molecules, such as $A \beta$ oligomers, $\alpha \beta$-crystallin that signals to elevate APP protein was reported (Fischer et al., 2013). Upregulation of iNOS enzyme suggested that cell stress in GNE myopathy is mainly due to NO-related free radicals (Fischer et al., 2013). In GNEM patients and mouse model, proteins were found to be highly modified with S-nitrosylation (Cho et al., 2017). In AD, generation of NO correlates with the activation of iNOS in glial cells. Generation of NO by iNOS is robust and render neurotoxicity, contributing to neuronal death and injury (Zhao et al., 2014). Atrogenes and oxidative stress response proteins are highly upregulated in hyposialylated condition and supplementation with sialic acid restores ROS levels in muscle cells (Cho et al., 2017). Additionally, in HEK293 cell based model system for GNEM overexpressing pathologically relevant GNE mutation, PrdxIV, an ER resident Peroxiredoxin was found to be downregulated. The downregulation of Prdx IV may disturb the redox state of ER, affecting proper folding of proteins eventually leading to ER stress (Chanana et al., 2017). Also expression level of Prdx I and Prdx IV was substantially decreased in post-mortem brain of $\mathrm{AD}$ with higher level of protein oxidation (Majd and Power, 2018). These studies suggest that oxidative stress may be common to both the 
disorders. ER based peroxiredoxins may play an important role in the pathology of both the diseases.

\section{Role of Endoplasmic Reticulum and Chaperones in Protein Aggregation}

Endoplasmic reticulum is an important cellular organelle involved in proper folding and processing of proteins. Perturbation in functioning of ER leads to misfolding of proteins and eventually protein aggregation, which is the key feature in several neurodegenerative diseases. Accumulation of misfolded proteins in ER elicits ER stress and unfolded protein response (UPR) that triggers cell death by apoptosis to eliminate cell toxicity (Tabas and Ron, 2011). Misfolded proteins that are retained in ER undergo proteosomal degradation via ERassociated degradation or ERAD (Smith et al., 2011). Activation of UPR proteins such as IRE1 and chaperone, GRP78, have been reported in the cortex and hippocampal tissue of $\mathrm{AD}$ brain (Hoozemans et al., 2005; Lee et al., 2010a). Activation of UPR proteins such as IRE1 $\alpha$, PERK, and ATF6 have been reported in AD by Xiang et al. (2017). Even GNEM muscle biopsies revealed upregulation of different UPR proteins including GRP78/BiP, GRP94, calnexin, and calreticulin, which are ER resident chaperones. The same study showed localization of GRP78/BiP and GRP94 with A $\beta$ in the ER (Li et al., 2013). Upregulation of chaperone GRP94 is reported in HEK cell based model of GNEM (Grover and Arya, 2014). Since upregulation of chaperones is also observed in GNEM, they may play an important role in protein aggregate and subsequently rimmed vacuole formation. Thus, small molecules affecting chaperone activity to enhance proper protein folding and inhibition of protein aggregation offer a promising therapeutic approach for GNEM.

Interestingly, calreticulin, molecular chaperone that modulates $\mathrm{Ca}^{2+}$ homeostasis, is downregulated in cortical neurons of $\mathrm{AD}$ patients and used as negative biomarker for $\mathrm{AD}$ progression (Lin et al., 2014). Another study reported that calreticulin co-localizes with both A $\beta$ and APP and helps in proper folding of $A \beta$ (Johnson et al., 2001). Stemmer et al have showed that calreticulin bound directly with Presenilin and Nicastrin molecular component of $\gamma$-secretase, along with $\mathrm{A} \beta$ (Stemmer et al., 2013). The binding of calreticulin with $\gamma$-secretase may direct the proper binding and cleavage of APP to $\mathrm{A} \beta$. Due to the downregulation of calreticulin in neurons, serum $\gamma$-secretase losses its proper cleaving activity leading to misfolded $\mathrm{A} \beta$ and accumulation in neurons. Altered calreticulin levels could affect protein folding in GNEM as calreticulin interact with phosphodiisomerase (PDI) to serve chaperone function in ER. PDI interacts with peroxiredoxin IV, which is downregulated in GNE deficient cells (Chanana et al., 2017). Thus, calreticulin may need further investigation towards its role as molecular chaperones in GNEM.

Heat Shock Proteins (HSPs) present in the cytosol also help protein to achieve native structure and avoid aggregation (Franklin et al., 2005; Paul and Mahanta, 2014). Elevated levels of HSP70 and HSP27 were found in brain tissues of AD patients (Perez et al., 1991; Renkawek et al., 1993). HSP70 has been reported to interfere with the secretory pathway of
APP by binding to APP and reducing A $\beta$ production. Along with HSP70, HSP90 has been shown to degrade A $\beta$ oligomers and tau via the proteasome degradation pathway ( $\mathrm{Lu}$ et al., 2014). Overexpression of HSP70 and HSP90 helps to maintain tau homeostasis and increases its solubility, thereby preventing aggregation (Petrucelli et al., 2004). Overexpression of the chaperones also prevents the activation of Caspases, which may lead to neuronal death due to accumulation of aggregated proteins (Sabirzhanov et al., 2012). Proteomic study on GNEM patient biopsies also indicates an increase in HSP70, Crystallin and HSPB1 levels (Sela et al., 2011). Thus, more intensive research is demanded to explore chaperones as therapeutic drug targets for GNEM that can reduce protein aggregation and inhibit rimmed vacuole formation.

\section{Autophagy in AD and GNEM}

Autophagy is the major degradative pathway for recycling of various proteins and organelles inside the cell, as it is essential for maintaining a balance between protein synthesis and degradation (Yang et al., 2009). Autophagy has been reported to be elevated when cells sense any kind of stress (Kwang et al., 2008). In AD, number of autophagosomes increase indicative of impaired recycling of cellular constituents (Funderburk et al., 2010). Mutation in Presenilin-1 gene affects lysosome mediated autophagy, reduces $\mathrm{p} 62$ protein levels leading to imbalance in tau proteostasis (Chui et al., 1999; Lee et al., 2010b; Tung et al., 2014). Many genes common to autophagy and $\mathrm{AD}$ pathology have been identified such as autophagy-related 7 (ATG7), BCL2, Beclin 1 (BECN1/ATG6), cyclin dependent kinase 5 (CDK5), Cathepsin D (CTSD), microtubule associated protein tau (MAPT/TAU), Presenilin-1, $\alpha$-Synuclein (SNCA/PARK1/NACP), Ubiquitin 1 etc., (Uddin et al., 2018). A $\beta$ accumulated intracellularly also regulates autophagy (Son et al., 2012). Tau pro-aggregates act as targets for macrophagy and chaperone mediated autophagy (Zare-Shahabadi et al., 2015).

Rimmed vacuoles observed in GNEM pathology are also defined as clusters of autophagic vacuoles and multi-lamellar bodies, which contain congophilic amyloid proteins, ubiquitin and tau proteins (Nonaka et al., 2005). Higher expression of lysosomal-associated membrane proteins (LAMPs), LC3 and various other lysosomal proteins involved in autophagic pathway were observed in the skeletal muscle of the mice model for GNEM (Malicdan et al., 2007). Differential regulation of BCL2 in GNEM also supports that some common proteins of autophagy pathway in AD may play a role in GNEM autophagic vacuole formation. A comparison of the autophagic mechanisms in AD vs. GNEM is shown in Figure 1. Thus, it would be of interest to study and identify novel targets causing autophagy in GNEM and several autophagy stimulating drugs for $\mathrm{AD}$ may serve as therapeutic option for myopathy.

\section{Cell Death and Apoptosis}

Cell death is the most common feature of the neurodegenerative diseases and occurs massively. In $\mathrm{AD}$, neuronal loss is mainly in cerebral cortex and limbic lobe (Alzheimer's Association, 2017). There are two major pathways for apoptosis, extrinsic pathway and intrinsic pathway. The extrinsic pathway involves 


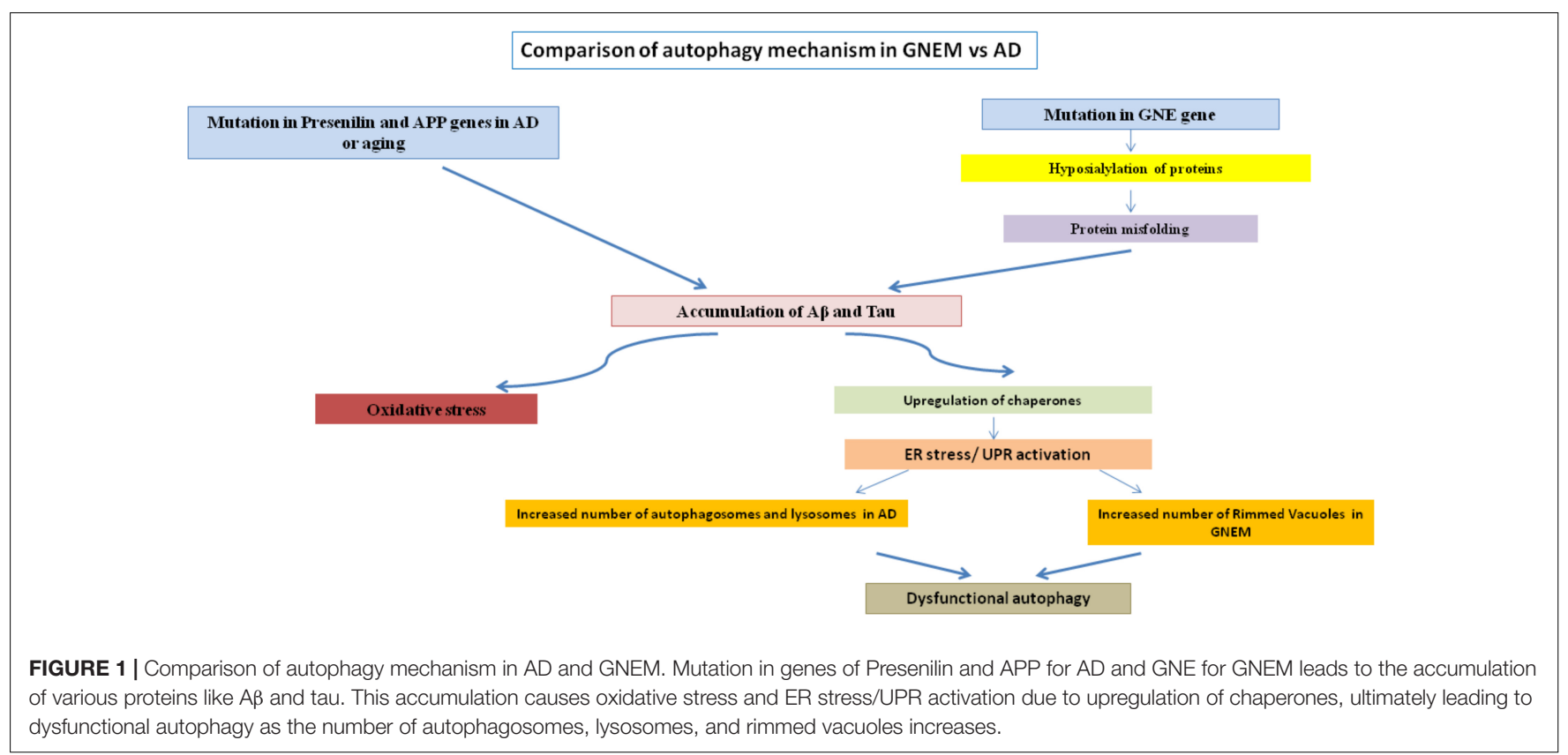

cell surface receptors like TNF in which the binding of $A \beta$ or $A \beta$ oligomers to these receptors remains to be established but the pattern of activation of downstream Caspases (e.g., Caspases 2 and 8) involved in the extrinsic pathway is mediated by $A \beta$ (Ghavami et al., 2014). In the intrinsic pathway, $A \beta$ plays an important role as its intracellular accumulation in the ER cause ER stress and when it binding to a mitochondrial alcohol dehydrogenase leads to mitochondrial stress followed by activation of the downstream apoptotic markers (Lustbader et al., 2004). The upstream mediators of the apoptotic processes are yet to be determined, but the Caspases are activated in the process, which cleaves the tau protein leading to NFT formation (Dickson, 2004). Therefore, in AD, proteolysis of both APP and tau takes place leading to abnormal proteins, which aggregate and form lesions of fibrils extracellularly and intracellularly. Thus, direct involvement of Caspases in apoptosis of neurons is not yet established but many Caspases have been found to play a role in regulation of neuronal death upon $A \beta$ accumulation (Behl, 2000; Dickson, 2004). A $\beta(1-42)$ exposure leads to down regulation of anti-apoptotic proteins like $\mathrm{Bcl}-2$ and upregulation of pro-apoptotic proteins like Bax, cytochrome-c and cleaved caspases in PC12 cells (Chen et al., 2018). Altered levels of various microRNAs that target neuropathological mechanisms have been reported in AD (Ma et al., 2017; Dehghani et al., 2018). Activation of programmed necrosis leading to cell death is reported in the brain of AD patients (Caccamo et al., 2017). The suppression of apoptotic cell signaling pathway proteins such as p38 MAPK can rescue tau pathology in AD (Maphis et al., 2016). These study suggest that various effector molecules targeting signaling proteins in the apoptotic pathway can play a role is preventing cell apoptosis caused due to $A \beta$ accumulation or tau dysfunction and hence potential drug molecules for AD.

In GNEM, degeneration is seen in the myofibrils of the patient muscle biopsies, which might lead to rimmed vacuole formation
(Yan et al., 2001). Similar to AD, activation of Caspases 3 and 9 was observed in the myoblast cells of the GNEM patient with M743T kinase mutation (Amsili et al., 2007). Along with this, increased pAKT levels was observed which suggests impairment in the apoptotic event (Amsili et al., 2007). Mitochondrial dependent apoptosis and disruption in both the structure and function of the mitochondria was observed in HEK cell based model system of GNEM over-expressing pathologically relevant GNE mutation (Singh and Arya, 2016). Also, activation of PTEN and PDK1 was observed in the myoblasts which might lead to muscle loss and on stimulation with insulin, activates PI3K and downstream signaling through AKT causing the activation of cell survival pathway (Harazi et al., 2014). Increased Anoikis, apoptosis due to loss of anchorage to extracellular matrix, was observed in pancreatic carcinoma cells when the GNE gene was silenced. Additionally, the level of CHOP has been reported to increase in GNE deficient cells indicative of apoptosis through ATF4-ATF3-CHOP pathway (Kemmner et al., 2012). Increased apoptosis due to internalization of $\mathrm{A} \beta$ peptides in hyposialylated C2C12 myotubes and skeletal muscles was observed in the patients of GNEM (Bosch-Morató et al., 2016). This suggests that sialylation has a role in $\mathrm{A} \beta$ uptake and cell apoptosis and molecules involved in apoptotic pathway can be therapeutic targets. Thus, molecular and cellular phenomenon for apoptosis in $\mathrm{AD}$ and GNEM seem to overlap despite difference in cell types, neuron vs. muscle cell, respectively.

A comparison of the apoptotic mechanisms in AD vs. GNEM has been described in Figure 2. Interestingly, treatment of GNE deficient cells with Insulin Growth Factor seems to rescue the apoptotic phenotype and hence could be a potential therapeutic target that counters apoptotic cell toward cell survival (Singh et al., 2018). In summary, proteins and drug molecules that rescue cell death phenomenon in AD by targeting common proteins, can be explored for GNEM therapy. 


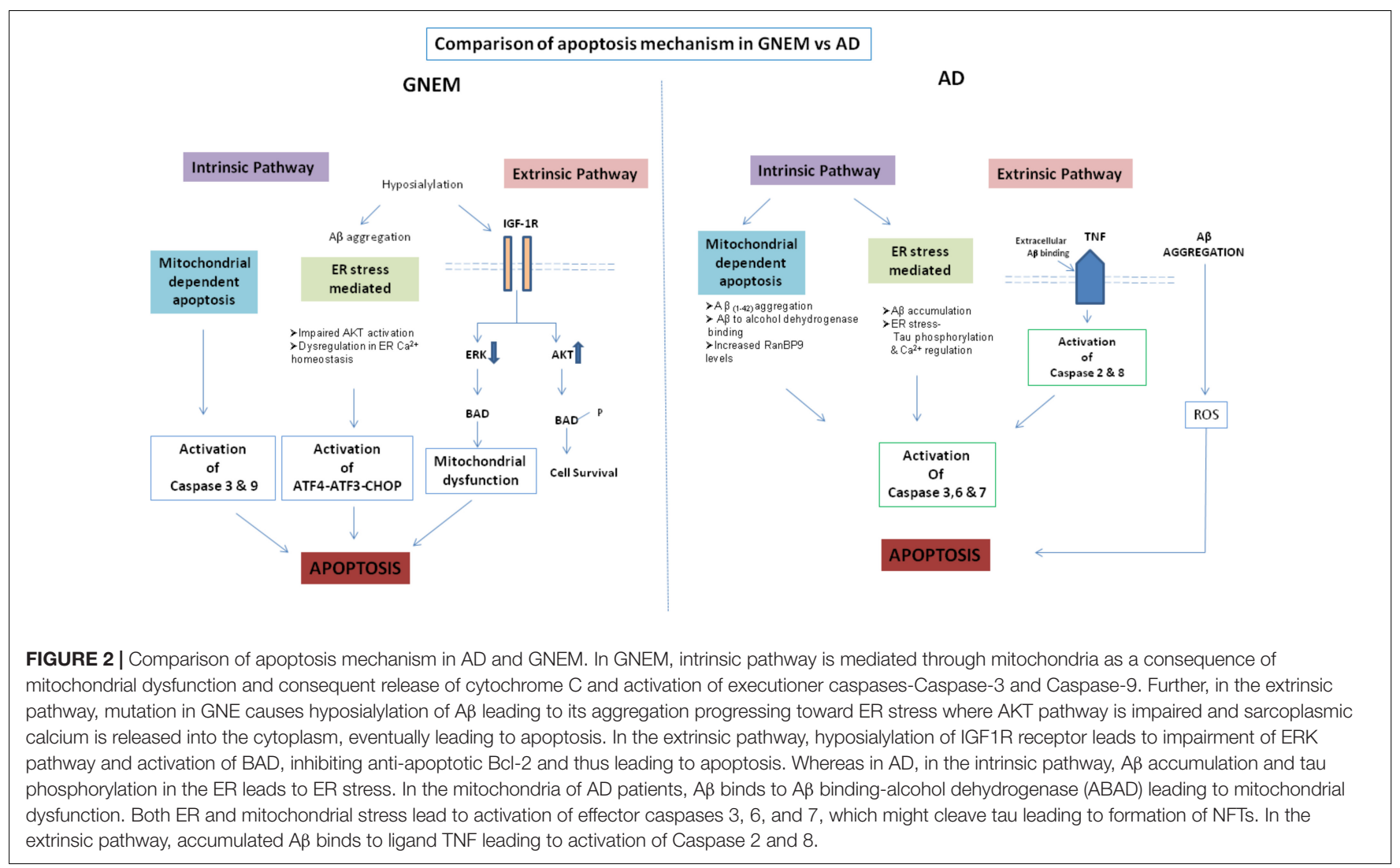

A complete comparison of molecular and cellular changes in $\mathrm{AD}$ and GNEM are listed in Table 2.

\section{TREATMENT}

There is no cure for $\mathrm{AD}$ till date as the medications available only help to control the symptoms of $\mathrm{AD}$. The $\mathrm{AD}$ drug therapy includes drugs, which target neurotransmitter system of the brain such as Acetylcholinesterase (Ach esterase) inhibitors that increases neurotransmitter levels at synaptic junctions (Schenk et al., 2012). Three FDA approved acetylcholinesterase inhibitors are Rivastigmine, Galantamine (for mild $\mathrm{AD}$ ), and Donepezil (for all stages of $\mathrm{AD}$ ) are available (Schenk et al., 2012). Also Memantine, antagonist for $N$-methyl-D-aspartate (NMDA) receptor is used in combination with Ach esterase inhibitor. None of the pharmacological drugs are able to stop the damage and destruction of the neurons therefore, making the disease fatal.

Since, $A \beta$ accumulation is one of the major causes leading to the disease; therefore drugs, which can lower the amount of $A \beta$ accumulation in the brain are of prime importance. Secretase inhibitor drugs, inhibit the cleavage of APP into $\mathrm{A} \beta$, therefore minimizing their accumulation (Imbimbo and Giardina, 2011). Another set of drugs used as a passive vaccination strategy in the form of antibodies, help in the clearance of $A \beta$ species (Schenk et al., 2012). Several drugs were developed which completed Phase-III clinical trials but failed to demonstrate their efficacy in patients. The passive vaccination strategy in case of tau also proved to be ineffective (Wischik et al., 2014). A major limitation with respect to effectiveness of antiamyloid drugs was thought to be late diagnosis of the disease. Thus, research focussing on the stage of initiation of amyloid formation could offer better drug targets. Indeed aducanumab, human monoclonal antibody, selective for aggregated form of $\mathrm{A} \beta$ showed reduced amyloid uptake and improved cognitive function in early AD patients (Scheltens et al., 2016).

In case of GNEM also, there is no treatment therapy available, which could reverse disease progression and stop muscle degeneration. Administration of $N$-acetylmannosamine, neuraminic acid, and sialyllactose in the mouse models of GNEM improved survival of the mouse by reduction in rimmed vacuole formation and $\beta$-amyloid deposition (Yonekawa et al., 2014). Gene therapy by administration of GNE gene lipoplex through intravenous infusion to the patients leads to an improvement in muscle strength and increased cell surface sialylation (Nemunaitis et al., 2010). An FDA approved molecular chaperone aiding in protein folding - 4-PBA (4-phenyl butyrate) has been proposed for GNEM (Krause, 2015). Anti-ActII activin antibody (bimagrumab or BYM338), an atrophic protein has been found to be helpful in preventing muscle atrophy in GNEM (Krause, 2015). Some of the compounds are under clinical trials such as sialic acid precursor, $\mathrm{N}$-acetylmannosamine (ManNAc), and extended release sialic acid form, aceneuramic acid. However, due to lack of statistical significance in the cohort of patient study, the compound was discontinued by Ultragenyx (MoriYoshimura and Nishino, 2015; Argov et al., 2016). 
TABLE 2 | Comparison of the molecular and cellular changes in AD and GNEM.

\begin{tabular}{|c|c|c|}
\hline & \multicolumn{2}{|c|}{ Molecular and cellular changes in AD and GNEM } \\
\hline & AD & GNEM \\
\hline Glycosylation & $\begin{array}{l}\text { - Impaired glucose metabolism } \\
\text { - Glycosylation of proteins affected }\end{array}$ & - Glycosylation of NCAM, integrin, $\alpha$-dystroglycan, IGF1R, neprilysin \\
\hline Sialic acid involvement & $\begin{array}{l}\text { Sialic acid dependent binding of A } \beta \text { to cells } \\
\text { - Decrease Level sialyltransferases }\end{array}$ & $\begin{array}{l}\text { Low Sialic acid production } \\
\text { - Hyposialylation of glycoproteins. }\end{array}$ \\
\hline Mitochondrial dysfunction & $\begin{array}{l}\text { - Mitochondria number reduced } \\
\text { - A } \beta \text { accumulation in mitochondria } \\
\text { - Impaired TCA cycle } \\
\text { - Mutation in mtDNA and cytochrome c oxidase } \\
\text { - Impaired mitochondrial trafficking }\end{array}$ & $\begin{array}{l}\text { - Vacuolar and swollen mitochondria } \\
\text { - Increased branching of mitochondria } \\
\text { - Upregulation of mitochondrial proteins like COX, Cytochrome C } \\
\text { Oxidase, ATPases, NADH dehydrogenase }\end{array}$ \\
\hline Oxidative stress & $\begin{array}{l}\text { - Neurotoxicity and protein oxidation due to accumulated A } \beta \\
\text { - Increased p-Tau } \\
\text { - S-nitrosylation of different proteins like Cdk5, PDI, ApoE }\end{array}$ & $\begin{array}{l}\text { - Upregulation of cell stress molecule } \\
\text { - PrdxIV downregulated } \\
\text { - Proteins found to be highly S-nitrosylated }\end{array}$ \\
\hline ER stress & $\begin{array}{l}\text { - XBP1 mRNA splicing leading to activation of IRE1 } \alpha \\
\text { - GRP78/BiP, GRP94, calnexin and calreticulin upregulated } \\
\text { - Co-localization of GRP78/BiP GRP94 and calreticulin with A } \beta \\
\text { - Calreticulin binds with presenilin and neprisilin }\end{array}$ & $\begin{array}{l}\text { - Upregulation of different UPR pathway proteins such as GRP78, } \\
\text { GRP94, Calreticulin and Calnexin }\end{array}$ \\
\hline Protein aggregation & - $A \beta$ and $p$-tau proteins & - $\beta$-amyloid, phosphorylated Tau, TDP-43, $\alpha$-synuclein \\
\hline Chaperone involvement & $\begin{array}{l}\text { - HSE (Heat Shock Element) associated with APP gene promoter } \\
\text { - Elevated levels of HSP70 and HSP27 } \\
\text { - HSP90 and HSP70 degrades A } \beta \text { oligomers and tau } \\
\text { - Higher levels of HSP70 and HSP90 promotes the binding of tau to } \\
\text { the microtubules }\end{array}$ & $\begin{array}{l}\text { - Upregulation of various chaperones } \\
\text { - The mutant protein preferentially retained in the ER }\end{array}$ \\
\hline Apoptosis & $\begin{array}{l}\text { - Activation of downstream caspases mediated by A } \beta \\
\text { - Caspases cleaves the Tau protein } \\
\text { - Nuclear chromatin clumping and apoptotic bodies }\end{array}$ & $\begin{array}{l}\text { - Degeneration in myofibrils } \\
\text { - Activation of Caspases } 3 \text { and } 9 \\
\text { - Mitochondrial dependent apoptosis and disruption of mitochondria } \\
\text { - Increased Anoikis } \\
\text { - Increased levels of CHOP }\end{array}$ \\
\hline Autophagy & $\begin{array}{l}\text { - Failure of autophagy } \\
\text { - Increased number of autophagosomes and lysosomes } \\
\text { - Rab7 and LAMP proteins dysregulated }\end{array}$ & $\begin{array}{l}\text { - Rimmed vacuoles-clusters of the autophagic vacuoles and } \\
\text { multi-lamellar bodies } \\
\text { - Higher expression of lysosomal-associated membrane proteins } \\
\text { (LAMPs), LC3 }\end{array}$ \\
\hline Inflammation & Occurs & Occurs rarely \\
\hline Cytoskeleton framework & $\begin{array}{l}\text { - Aggregation of hyperphosphorylated tau } \\
\text { - Inactivation of cofilin } 1, \mathrm{SSH} 1 \\
\text { - Rac1 leads to APP accumulation } \\
\text { - RhoA increases A } \beta \\
\text { - Cofilin-actin rod results in synaptic loss }\end{array}$ & $\begin{array}{l}\text { - GNE interact with Collapsin Response Mediator Protein-1 } \\
(\text { CRMP-1), } \alpha \text {-actinin-1 and } \alpha \text {-actinin-2 } \\
\text { - } \beta \text {-integrin mediated cell adhesion affected } \\
\text { - A } \beta \text { induces FAK }\end{array}$ \\
\hline
\end{tabular}

Recent studies in GNEM indicate that sialic acid supplementation alone may not be sufficient to rescue disease phenotype. As discussed above several other cellular phenomena affect GNEM including accumulation of aggregated proteins such as $\beta$-amyloid and tau proteins. Sialic acid has been shown to affect $\beta$-amyloid uptake in $\mathrm{C} 2 \mathrm{C} 12$ myoblast indicating role of sialic acid in $\beta$-amyloid uptake (Bosch-Morató et al., 2016). Thus, drug molecules affecting $\beta$-amyloid uptake and initiation of $\mathrm{A} \beta$ accumulation may serve as better therapeutic targets and offer common mechanism for $\mathrm{AD}$ as well as GNEM.

\section{CONCLUSION}

While much is known for AD, GNEM is poorly understood rare disease. Lack of number of patient samples for GNEM also limits the study. Also, absence of appropriate animal model system for GNEM, as $\mathrm{GNE}^{-/-}$mice are embryonically lethal at day E8.5, restricts the understanding for genotype to phenotype co-relation. There could be some interesting leads from $\mathrm{AD}$ studies that could help explore GNEM pathomechanism. While both diseases have lot of similarities at cellular level such as $\mathrm{A} \beta$ amyloid deposition, protein aggregation, autophagic vacuoles, major difference is that in $\mathrm{AD}$, brain/neurons are affected while in GNEM, only muscles in particular anterior tibialis muscle cells are affected. No changes in the neurons of GNEM patients are reported. It would be of interest to study the stage of $A \beta$ deposition in GNE deficient cells and whether protein aggregation could be prevented to slow the disease progression for GNEM. Also, whether there is any genetic predisposition of AD or GNEM in patient families would be important to understand epigenetics of these neurodegenerative disorders. Future studies could be planned toward deciphering common therapeutic targets for these disorders. 


\section{AUTHOR CONTRIBUTIONS}

SD and RY have written the first draft of the manuscript. PC and RA revised and improved the first draft. RY prepared the tables and Figure 2. PC prepared Figure 1. RA edited and finalized the version. All authors have seen and agreed on the finally submitted version of the manuscript.

\section{FUNDING}

This work was supported by grants from the UPOE-II (Project ID:16), University Grants Commission, India, DST PURSE II (DST/SR/PURSE Phase II/11, Department of Science and Technology, Government of India and SERB (Science and

\section{REFERENCES}

Aisa, B., Gil-Bea, F. J., Solas, M., García-Alloza, M., Chen, C. P., Lai, M. K., et al. (2010). Altered NCAM expression associated with the cholinergic system in alzheimer's disease. J. Alzheimers Dis. 20, 659-668. doi: 10.3233/JAD-2010-1398

Alzheimer's Association (2017). Alzheimer's disease facts and figures. Alzheimers Dement. 13, 325-373. doi: 10.1016/j.jalz.2017.02.001

Amsili, S., Shlomai, Z., Levitzki, R., Krause, S., Lochmuller, H., Ben-Bassat, H., et al. (2007). Characterization of hereditary inclusion body myopathy myoblasts: possible primary impairment of apoptotic events. Cell Death Differ. 14, 1916-1924. doi: 10.1038/sj.cdd.4402208

Amsili, S., Zer, H., Hinderlich, S., Krause, S., Becker-Cohen, M., MacArthur, D. G., et al. (2008). UDP-N-acetylglucosamine-2-epimerase/ $\mathrm{N}$-acetylmannosamine kinase (GNE) binds to alpha-actinin 1: novel pathways in skeletal muscle? PLoS One 3:e2477. doi: 10.1371/journal.pone.0002477

Anada, R. P., Wong, K. T., Malicdan, M. C., Goh, K. J., Hayashi, Y., Nishino, I., et al. (2014). Absence of beta-amyloid deposition in the central nervous system of a transgenic mouse model of distal myopathy with rimmed vacuoles. Amyloid 21, 138-139. doi: 10.3109/13506129.2014.889675

Anderson, J. L., Head, S. I., Rae, C., and Morley, J. W. (2002). . Brain function in Duchenne muscular dystrophy. Brain 125(Pt 1), 4-13. doi: 10.1093/brain/ awf012

Andreyev, A. Y., Kushnareva, Y. E., and Starkov, A. A. (2005). Mitochondrial metabolism of reactive oxygen species. Biochemistry 70, 200-214.

Ankarcrona, M., Mangialasche, F., and Winblad, B. (2010). Rethinking Alzheimer's disease therapy: Are mitochondria the key? J. Alzheimers Dis. 20, S579-S590. doi: 10.3233/JAD-2010-100327

Argov, Z., Caraco, Y., Lau, H., Pestronk, A., Shieh, P. B., Skrinar, A., et al. (2016). Aceneuramic acid extended release administration maintains upper limb muscle strength in a 48-week study of subjects with GNE myopathy: results from a phase 2, randomized, controlled study. J. Neuromuscul. Dis. 3, 49-66. doi: $10.3233 /$ JND- 159900

Argov, Z., and Yarom, R. (1984). "Rimmed vacuole myopathy" sparing the quadriceps. A unique disorder in iranian jews. J. Neurol. Sci. 64, 33-43. doi: 10.1016/0022-510X(84)90053-4

Ariga, T., Kobayashi, K., Hasegawa, A., Kiso, M., Ishida, H., and Miyatake, T. (2001). Characterization of high-affinity binding between gangliosides and amyloid beta-protein. Arch Biochem. Biophys. 388, 225-230. doi: 10.1006/abbi. 2001.2304

Bamburg, J. R., Bernstein, B. W., Davis, R. C., Flynn, K. C., Goldsbury, C., Jensen, J. R., et al. (2010). ADF/Cofilin-actin rods in neurodegenerative diseases. Curr. Alzheimers Res. 7, 241-250. doi: 10.2174/156720510791050902

Barnes, D. E., and Yaffe, K. (2011). The projected effect of risk factor reduction on Alzheimer's disease prevalence. Lancet Neurol. 10, 819-828. doi: 10.1016/ S1474-4422(11)70072-2

Barone, E., Mosser, S., and Fraering, P. C. (2014). Inactivation of brain Cofilin-1 by age, Alzheimer's disease and $\gamma$-secretase. Biochim. Biophys. Acta 1842(12 Pt A), 2500-2509. doi: 10.1016/j.bbadis.2014.10.004
Engineering Research Board) EMR/2015/001798, Government of India. We acknowledge Jawaharlal Nehru University, New Delhi for providing financial assistance towards publication and infrastructure.

\section{ACKNOWLEDGMENTS}

We thank Prof. M. A. Kamal, King Fahd Medical Research Center, King Abdulaziz University, Kingdom of Saudi Arabia for fruitful suggestions regarding conceptualizing the review. We also thank Dr. Kulvinder Singh Saini, Professor of Biotechnology, Department of Biology, King Abdulaziz University, Jeddah, Saudi Arabia for support and encouragement.

Beach, T. G., Monsell, S. E., Phillips, L. E., and Kukull, W. (2012). Accuracy of the clinical diagnosis of Alzheimer disease at National Institute on Aging Alzheimer Disease Centers, 2005-2010. J. Neuropathol. Exp. Neurol. 71, 266-273. doi: 10.1097/NEN.0b013e31824b211b

Behl, C. (2000). Apoptosis and Alzheimer's disease. J. Neural Transm. 107, 13251344. doi: 10.1007/s007020070021

Bennmann, D., Weidemann, W., Thate, A., Kreuzmann, D., and Horstkorte, R. (2016). Aberrant O-GlcNAcylation disrupts GNE enzyme activity in GNE myopathy. FEBS J. 283, 2285-2294. doi: 10.1111/febs.13729

Bhattacharya, S., Khadilkar, S. V., Nalini, A., Ganapathy, A., Mannan, A. U., Majumder, P. P., et al. (2018). Mutation spectrum of GNE myopathy in the Indian sub-continent. J Neuromuscul. Dis. 5, 85-92. doi: 10.3233/JND170270

Boo, J. H., Sohn, J. H., Kim, J. E., Song, H., and Mook-Jung, I. (2008). Racl changes the substrate specificity of gamma-secretase between amyloid precursor protein and Notch1. Biochem. Biophys. Res. Commun. 372, 913-917. doi: 10.1016/j.bbrc. 2008.05.153

Bosch-Morató, M., Iriondo, C., Guivernau, B., Valls-Comamala, V., Vidal, N., Olivé, M., et al. (2016). Increased amyloid $\beta$-peptide uptake in skeletal muscle is induced by hyposialylation and may account for apoptosis in GNE myopathy. Oncotarget 7, 13354-13371. doi: 10.18632/oncotarget.7997

Broccolini, A., Gidaro, T., De Cristofaro, R., Morosetti, R., Gliubizzi, C., Ricci, E., et al. (2008). Hyposialylation of neprilysin possibly affects its expression and enzymatic activity in hereditary inclusion-body myopathy muscle. J. Neurochem. 105, 971-981. doi: 10.1111/j.1471-4159.2007. 05208.x

Bubber, P., Haroutunian, V., Fisch, G., Blass, J. P., and Gibson, G. E. (2005). Mitochondrial abnormalities in Alzheimer brain: mechanistic implications. Ann. Neurol. 57, 695-703. doi: 10.1002/ana.20474

Caccamo, A., Branca, C., Piras, I. S., Ferreira, E., Huentelman, M. J., Liang, W. S., et al. (2017). Necroptosis activation in Alzheimer's disease. Nat. Neurosci. 20, 1236-1246. doi: 10.1038/nn.4608

Castellani, R., Hirai, K., Aliev, G., Drew, K. L., Nunomura, A., Takeda, A., et al. (2002). Role of mitochondrial dysfunction in Alzheimer's disease. J. Neurosci. Res. 70, 357-360. doi: 10.1002/jnr.10389

Cha, M. Y., Han, S. H., Son, S. M., Hong, H. S., Choi, Y. J., Byun, J., et al. (2012). Mitochondria-specific accumulation of amyloid $\beta$ induces mitochondrial dysfunction leading to apoptotic cell death. PLoS One 7:e34929. doi: 10.1371/ journal.pone.0034929

Chanana, P., Padhy, G., Bhargava, K., and Arya, R. (2017). Mutation in GNE downregulates peroxiredoxin IV altering ER redox homeostasis. NeuroMolecular Med. 19, 525-540. doi: 10.1007/s12017-017-8467-5

Chen, K., Lu, Y., Liu, C., Zhang, L., Fang, Z., and Yu, G. (2018). Morroniside prevents $\mathrm{H} 2 \mathrm{O} 2$ or $\mathrm{A} \beta 1-42$-induced apoptosis via attenuating JNK and p38 MAPK phosphorylation. Eur. J. Pharmacol. 834, 295-304. doi: 10.1016/j.ejphar. 2018.07.047

Cho, A., Malicdan, M. C. V., Miyakawa, M., Nonaka, I., Nishino, I., and Noguchi, S. (2017). Sialic acid deficiency is associated with oxidative stress leading to 
muscle atrophy and weakness in the GNE myopathy. Hum. Mol. Genet. 274, 19792-19798. doi: 10.1093/hmg/ddx192

Chornenkyy, Y., Wang, W.-X., Wei, A., and Nelson, P. T. (2018). Alzheimer's disease and Type 2 Diabetes mellitus are distinct diseases with potential overlapping metabolic dysfunction upstream of observed cognitive decline. Brain Pathol. doi: 10.1111/bpa.12655 [Epub ahead of print].

Chui, D. H., Tanahashi, H., Ozawa, K., Ikeda, S., Checler, F., Ueda, O., et al. (1999). Transgenic mice with Alzheimer presenilin 1 mutations show accelerated neurodegeneration without amyloid plaque formation. Nat. Med. 5, 560-564. doi: $10.1038 / 8438$

Chun, Y. S., Park, Y., Oh, H. G., Kim, T. W., Yang, H. O., Park, M. K., et al. (2015). O-GlcNAcylation promotes non-amyloidogenic processing of amyloid$\beta$ protein precursor via inhibition of endocytosis from the plasma membrane. J. Alzheimers Dis. 44, 261-275. doi: 10.3233/JAD- 140096

DeHart, G. W., and Jones, J. C. R. (2004). Myosin-mediated cytoskeleton contraction and Rho GTPases regulate laminin-5 matrix assembly. Cell Motil. Cytoskeleton 57, 107-117. doi: 10.1002/cm.10161

Dehghani, R., Rahmani, F., and Rezaei, N. (2018). MicroRNA in Alzheimer's disease revisited: implications for major neuropathological mechanisms. Rev. Neurosci. 29, 161-182. doi: 10.1515/revneuro-2017-0042

Dickson, D. W. (2004). Apoptotic mechanisms in Alzheimer neurofibrillary degeneration: cause or effect? J. Clin. Investigat. 114, 23-27. doi: 10.1172/ JCI22317

Eisenberg, I., Novershtern, N., Itzhaki, Z., Becker-Cohen, M., Sadeh, M., Willems, P. H., et al. (2008). Mitochondrial processes are impaired in hereditary inclusion body myopathy. Hum. Mol. Genet. 17, 3663-3674. doi: 10.1093/hmg/ddn261

Feng, Y., and Wang, X. (2012). Antioxidant therapies for Alzheimer's disease. Oxid. Med. Cell. Longev. 2012:472932. doi: 10.1155/2012/472932

Fischer, C., Kleinschnitz, K., Wrede, A., Muth, I., Kruse, N., Nishino, I., et al. (2013). Cell stress molecules in the skeletal muscle of GNE myopathy. BMC Neurol. 13:24. doi: 10.1186/1471-2377-13-24

Franklin, T. B., Krueger-Naug, A. M., Clarke, D. B., Arrigo, A. P., and Currie, R. W. (2005). The role of heat shock proteins Hsp70 and Hsp27 in cellular protection of the central nervous system. Int. J. Hyperthermia 21, 379-392. doi: 10.1080/02656730500069955

Fukui, H., Diaz, F., Garcia, S., and Moraes, C. T. (2007). Cytochrome c oxidase deficiency in neurons decreases both oxidative stress and amyloid formation in a mouse model of Alzheimer's disease. Proc. Natl. Acad. Sci. U.S.A. 104, 14163-14168. doi: 10.1073/pnas.0705738104

Funderburk, S. F., Marcellino, B. K., and Yue, Z. (2010). Cell "self-eating" (autophagy) mechanism in Alzheimer's disease. Mt. Sinai J. Med. 77, 59-68. doi: $10.1002 / \mathrm{msj} .20161$

Garden, G. A., and La Spada, A. R. (2012). Intercellular (Mis)communication in neurodegenerative disease. Neuron 73, 886-901. doi: 10.1016/j.neuron.2012. 02.017

Ghavami, S., Shojaei, S., Yeganeh, B., Ande, S. R., Jangamreddy, J. R., Mehrpour, M., et al. (2014). Autophagy and apoptosis dysfunction in neurodegenerative disorders. Prog. Neurobiol. 112, 24-49. doi: 10.1016/j.pneurobio.2013. 10.004

Goate, A., Chartier-Harlin, M. C., Mullan, M., Brown, J., Crawford, F., Fidani, L., et al. (1991). Segregation of a missense mutation in the amyloid precursor protein gene with familial Alzheimer's disease. Nature 349, 704-706. doi: 10. 1038/349704a0

Gong, C. X., Liu, F., Grundke-Iqbal, I., and Iqbal, K. (2005). Post-translational modifications of tau protein in Alzheimer's disease. J. Neural Transm. 112, 813-838. doi: 10.1007/s00702-004-0221-0

Grover, S., and Arya, R. (2014). Role of UDP-N-acetylglucosamine2-epimerase/Nacetylmannosamine kinase (GNE) in ??1-integrin-mediated cell adhesion. Mol. Neurobiol. 50, 257-273. doi: 10.1007/s12035-013-8604-6

Han, H. Y., Zhang, J. P., Ji, S. Q., Liang, Q. M., Kang, H. C., Tang, R. H., et al. (2013). $\alpha \nu$ and $\beta 1$ integrins mediate $A \beta$-induced neurotoxicity in hippocampal neurons via the FAK signaling pathway. PLoS One 8:e64839. doi: 10.1371/journal.pone. 0064839

Hanger, D. P., Byers, H. L., Wray, S., Leung, K. Y., Saxton, M. J., Seereeram, A., et al. (2007). Novel phosphorylation sites in Tau from Alzheimer brain support a role for casein kinase 1 in disease pathogenesis. J. Biol. Chem. 282, 23645-23654. doi: 10.1074/jbc.M703269200
Harazi, A., Becker-Cohen, M., Zer, H., Moshel, O., Hinderlich, S., and MitraniRosenbaum, S. (2017). The interaction of UDP-N-acetylglucosamine 2Epimerase/N-Acetylmannosamine Kinase (GNE) and Alpha-actinin 2 is altered in GNE Myopathy M743T mutant. Mol. Neurobiol. 54, 2928-2938. doi: 10.1007/ s12035-016-9862-x

Harazi, A., Chaouat, M., Shlomai, Z., Levitzki, R., Becker-Cohen, M., Sadeh, M., et al. (2014). Survival-apoptosis associated signaling in GNE myopathycultured myoblasts. J. Recept Signal Transduct. Res. 35, 249-257. doi: 10.3109/ 10799893.2014.956755

Holtzman, D. M., Morris, J. C., and Goate, A. M. (2011)). Alzheimer's disease: the challenge of the second century. Sci. Transl. Med. 3:77sr1. doi: 10.1126/ scitranslmed.3002369

Hoozemans, J. J. M., Veerhuis, R., Van Haastert, E. S., Rozemuller, J. M., Baas, F., Eikelenboom, P., et al. (2005). The unfolded protein response is activated in Alzheimer's disease. Acta Neuropathol. 110, 165-172. doi: 10.1007/s00401-0051038-0

Huizing, M., and Krasnewich, D. M. (2009). Hereditary inclusion body myopathy: a decade of progress. Biochim. Biophys. Acta 1792, 881-887. doi: 10.1016/j. bbadis.2009.07.001

Huizing, M., Rakocevic, G., Sparks, S. E., Mamali, I., Shatunov, A., Goldfarb, L., et al. (2004). Hypoglycosylation of $\alpha$-dystroglycan in patients with hereditary IBM due to GNE mutations. Mol. Genet. Metab. 81, 196-202. doi: 10.1016/j. ymgme.2003.11.012

Hutton, M., and Hardy, J. (1997). The presenilins and Alzheimer's disease. Hum. Mol. Genet. 6, 1639-1646. doi: 10.1093/hmg/6.10.1639

Imbimbo, B. P., and Giardina, G. A. (2011). $\gamma$-Secretase Inhibitors and Modulators for the treatment of Alzheimer's disease: disappointments and hopes. Curr. Top. Med. Chem. 11, 1555-1570. doi: 10.2174/156802611795860942

Iqbal, K., Alonso, A. D. C., and Grundke-Iqbal, I. (2008). Cytosolic abnormally hyperphosphorylated tau but not paired helical filaments sequester normal MAPs and inhibit microtubule assembly. J. Alzheimers Dis. 14, 365-370. doi: 10.3233/JAD-2008-14402

Jay, C. M., Levonyak, N., Nemunaitis, G., Maples, P. B., and Nemunaitis, J. (2009). Hereditary inclusion body myopathy (HIBM2). Gene Regul. Syst. Biol. 3, 181-190. doi: 10.4137/GRSB.S2594

Jiang, T., Yu, J. T., Hu, N., Tan, M. S., Zhu, X. C., and Tan, L. (2014). CD33 in Alzheimer's disease. Mol. Neurobiol. 49, 529-535. doi: 10.1007/s12035-0138536- 1

Johnson, R. J., Xiao, G., Shanmugaratnam, J., and Fine, R. E. (2001). Calreticulin functions as a molecular chaperone for the beta-amyloid precursor protein. Neurobiol. Aging 22, 387-395. doi: 10.1016/S0197-4580(00)00247-5

Kanekura, K., Suzuki, H., Aiso, S., and Matsuoka, M. (2009). ER stress and unfolded protein response in amyotrophic lateral sclerosis. Mol. Neurobiol. 39, 81-89. doi: 10.1007/s12035-009-8054-3

Kemmner, W., Kessel, P., Sanchez-Ruderisch, H., Moller, H., Hinderlich, S., Schlag, P. M., et al. (2012). Loss of UDP-N-acetylglucosamine 2-epimerase/Nacetylmannosamine kinase (GNE) induces apoptotic processes in pancreatic carcinoma cells. FASEB J. 26, 938-946. doi: 10.1096/fj.11-186700

Kizuka, Y., Kitazume, S., and Taniguchi, N. (2017). N-glycan and Alzheimer's disease. Biochim. Biophys. Acta 1861, 2447-2454. doi: 10.1016/j.bbagen.2017. 04.012

Koistinen, H., Prinjha, R., Soden, P., Harper, A., Banner, S. J., Pradat, P.-F., et al. (2006). Elevated levels of amyloid precursor protein in muscle of patients with amyotrophic lateral sclerosis and a mouse model of the disease. Muscle Nerve 34, 444-450. doi: 10.1002/mus.20612

Köroğlu, Ç, Yılmaz, R., Sorgun, M. H., Solakoğlu, S., and S̨ener, Ö (2017). GNE missense mutation in recessive familial amyotrophic lateral sclerosis. Neurogenetics 18, 237-243. doi: 10.1007/s10048-017-0527-3

Krause, S. (2015). Insights into muscle degeneration from heritable inclusion body myopathies. Front. Aging Neurosci. 7:13. doi: 10.3389/fnagi.2015.00013

Kwang, W. K., Hwang, M., Moretti, L., Jaboin, J. J., Cha, Y. I., and Lu, B. (2008). Autophagy upregulation by inhibitors of caspase- 3 and mTOR enhances radiotherapy in a mouse model of lung cancer. Autophagy 4, 659-668. doi: 10.4161/auto.6058

Lackner, L. L. (2013). Determining the shape and cellular distribution of mitochondria: The integration of multiple activities. Curr. Opin. Cell Biol. 25, 471-476. doi: 10.1016/j.ceb.2013.02.011 
Lee, J. H., Won, S. M., Suh, J., Son, S. J., Moon, G. J., Park, U. J., et al. (2010a). Induction of the unfolded protein response and cell death pathway in Alzheimer's disease, but not in aged Tg2576 mice. Exp. Mol. Med. 42, 386-394. doi: 10.3858/emm.2010.42.5.040

Lee, J. H., Yu, W. H., Kumar, A., Lee, S., Mohan, P. S., Peterhoff, C. M., et al. (2010b). Lysosomal proteolysis and autophagy require presenilin 1 and are disrupted by Alzheimer-related PS1 mutations. Cell 141, 1146-1158. doi: 10. 1016/j.cell.2010.05.008

Letenneur, L., Launer, L. J., Andersen, K., Dewey, M. E., Ott, A., Copeland, J. R. M., et al. (2000). Education and the risk for Alzheimer's disease: sex makes a difference. EURODEM pooled analyses. Am. J. Epidemiol. 151, 1064-1071. doi: 10.1093/oxfordjournals.aje.a010149

Li, H., Chen, Q., Liu, F., Zhang, X., Li, W., Liu, S., et al. (2013). Unfolded Protein Response and activated degradative pathways regulation in GNE myopathy. PLoS One 8:e58116. doi: 10.1371/journal.pone.0058116

Lin, Q., Cao, Y., and Gao, J. (2014). Serum calreticulin is a negative biomarker in patients with Alzheimer's disease. Int. J. Mol. Sci. 15, 21740-21753. doi: $10.3390 /$ ijms 151221740

López-Otín, C., Blasco, M. A., Partridge, L., Serrano, M., and Kroemer, G. (2013). The hallmarks of aging. Cell 153, 1194-1217. doi: 10.1016/j.cell.2013.05.039

Lovell, M. A., Xiong, S., Xie, C., Davies, P., and Markesbery, W. R. (2004). Induction of hyperphosphorylated tau in primary rat cortical neuron cultures mediated by oxidative stress and glycogen synthase kinase-3. J. Alzheimers Dis. 6, 659-671. doi: 10.3233/JAD-2004-6610

Lu, R.-C., Tan, M.-S., Wang, H., Xie, A.-M., Yu, J.-T., and Tan, L. (2014). Heat shock protein 70 in Alzheimer's disease. Biomed. Res. Int. 2014, 1-8. doi: 10. 1155/2014/435203

Lustbader, J. W., Cirilli, M., Lin, C., Xu, H. W., Takuma, K., Wang, N., et al. (2004). ABAD directly links Abeta to mitochondrial toxicity in Alzheimer's disease. Science. 304, 448-452. doi: 10.1126/science.1091230

Ma, X., Liu, L., and Meng, J. (2017). MicroRNA-125b promotes neurons cell apoptosis and Tau phosphorylation in Alzheimer's disease. Neurosci. Lett. 661, 57-62. doi: 10.1016/j.neulet.2017.09.043

Maguire, T. M., and Breen, K. C. (1995). A decrease in neural sialyltransferase activity in Alzheimer's disease. Dement Geriatr. Cogn. Disord. 6, 185-190. doi: 10.1159/000106944

Maguire, T. M., Gillian, A. M., O’Mahony, D., Coughlan, C. M., and Breen, K. C. (1994). A decrease in serum sialyltransferase levels in Alzheimer's disease. Neurobiol. Aging 15, 99-102. doi: 10.1016/0197-4580(94)90149-X

Majd, S., and Power, J. H. (2018). Oxidative stress and decreased mitochondrial superoxide dismutase 2 and Peroxiredoxin 1 and 4 based mechanism of concurrent activation of AMPK and mTOR in Alzheimer's disease. Curr. Alzheimer Res. 15, 764-776. doi: 10.2174/1567205015666180223093020

Malicdan, M. C. V., Noguchi, S., Nonaka, I., Hayashi, Y. K., and Nishino, I. (2007). A Gne knockout mouse expressing human GNE D176V mutation develops features similar to distal myopathy with rimmed vacuoles or hereditary inclusion body myopathy. Hum. Mol. Genet. 16, 2669-2682. doi: 10.1093/hmg/ $\operatorname{ddm} 220$

Maphis, N., Jiang, S., Xu, G., Kokiko-Cochran, O. N., Roy, S. M., Van Eldik, L. J., et al. (2016). Selective suppression of the $\alpha$ isoform of p38 MAPK rescues late-stage tau pathology. Alzheimers Res. Ther. 8:54. doi: 10.1186/s13195-0160221-y

Mokhtar, S. H., Kim, M. J., Magee, K. A., Aui, P. M., Thomas, S., Bakhuraysah, M. M., et al. (2018). Amyloid-beta-dependent phosphorylation of collapsin response mediator protein-2 dissociates kinesin in Alzheimer's disease. Neural Regen. Res. 13, 1066-1080. doi: 10.4103/1673-5374.233451

Moniruzzaman, M., Ishihara, S., Nobuhara, M., Higashide, H., and Funamoto, S. (2018). Glycosylation status of nicastrin influences catalytic activity and substrate preference of $\gamma$-secretase. Biochem. Biophys. Res. Commun. 502, 98-103. doi: 10.1016/j.bbrc.2018.05.126

Montie, H. L., and Durcan, T. M. (2013). The cell and molecular biology of neurodegenerative diseases: an overview. Front. Neurol. 4:194. doi: 10.3389/ fneur.2013.00194

Mori-Yoshimura, M., and Nishino, I. (2015). Sialic acid replacement therapy for distal myopathy with rimmed vacuoles. Brain Nerve 67, 1115-1123.

Mosconi, L. (2005). Brain glucose metabolism in the early and specific diagnosis of Alzheimer's disease: FDG-PET studies in MCI and AD. Eur. J. Nucl. Med. Mol. Imaging 32, 486-510. doi: 10.1007/s00259-005-1762-7
Murray, H. C., Low, V. F., Swanson, M. E. V., Dieriks, B. V., Turner, C., Faull, R. L. M., et al. (2016). Distribution of PSA-NCAM in normal, Alzheimer's and Parkinson's disease human brain. Neuroscience 330, 359-375. doi: 10.1016/j. neuroscience.2016.06.003

Nakagawa, K., Kitazume, S., Oka, R., Maruyama, K., Saido, T. C., Sato, Y., et al. (2006). Sialylation enhances the secretion of neurotoxic amyloid$\beta$ peptides. J. Neurochem. 96, 924-933. doi: 10.1111/j.1471-4159.2005. 03595.x

Nalini, A., Gayathri, N., and Dawn, R. (2010). Distal myopathy with rimmed vacuoles: report on clinical characteristics in 23 cases. Neurol. India 58, 235-241. doi: 10.4103/0028-3886.63804

Nalini, A., Nishino, I., Gayathri, N., and Hayashi, Y. (2013). GNE myopathy in India. Neurol. India 61:371. doi: 10.4103/0028-3886.117609

Narici, M. V., and Maffulli, N. (2010). Sarcopenia: characteristics, mechanisms and functional significance. Br. Med. Bull. 95, 139-159. doi: 10.1093/bmb/ldq008

Nemunaitis, G., Maples, P. B., Jay, C., Gahl, W. A., Huizing, M., Poling, J., et al. (2010). Hereditary inclusion body myopathy: single patient response to GNE gene Lipoplex therapy. J. Gene. Med. 12, 403-412. doi: 10.1002/jgm. 1450

Nogalska, A., D’Agostino, C., Engel, W. K., Cacciottolo, M., Asada, S., Mori, K., et al. (2015). Activation of the unfolded protein response in sporadic inclusion-body myositis but not in hereditary GNE inclusion-body myopathy. J. Neuropathol. Exp. Neurol. 74, 538-546. doi: 10.1097/NEN.00000000000 00196

Noguchi, S., Keira, Y., Murayama, K., Ogawa, M., Fujita, M., Kawahara, G., et al. (2004). Reduction of UDP-N-acetylglucosamine 2-Epimerase/NAcetylmannosamine kinase activity and sialylation in distal Myopathy with rimmed vacuoles. J. Biol. Chem. 279, 11402-11407. doi: 10.1074/jbc. M313171200

Nonaka, I., Noguchi, S., and Nishino, I. (2005). Distal myopathy with rimmed vacuoles and hereditary inclusion body myopathy. Curr. Neurol. Neurosci. Rep. 5, 61-65. doi: 10.1007/s11910-005-0025-0

Norfray, J. F., and Provenzale, J. M. (2004). Alzheimer's disease: neuropathologic findings and recent advances in imaging. Am. J. Roentgenol. 182, 3-13. doi: 10.2214/ajr.182.1.1820003

Ott, A., Stolk, R. P., van Harskamp, F., Pols, H. A., Hofman, A., and Breteler, M. M. (1999). Diabetes mellitus and the risk of dementia: the rotterdam study. Neurology 53, 1937-1942. doi: 10.1212/WNL.53.9.1937

Paul, S., and Mahanta, S. (2014). Association of heat-shock proteins in various neurodegenerative disorders: Is it a master key to open the therapeutic door? Mol. Cell. Biochem. 386, 45-61. doi: 10.1007/s11010-013-1844-y

Peila, R., Rodriguez, B. L., and Launer, L. J. (2002). Type 2 diabetes, APOE gene, and the risk for dementia and related pathologies. Diabetes 51, 1256-1262. doi: 10.2337/diabetes.51.4.1256

Penzes, P., and Rafalovich, I. (2012). Regulation of the actin cytoskeleton in dendritic spines. Adv. Exp. Med. Biol. 970, 81-95. doi: 10.1007/978-3-70910932-8_4

Perez, N., Sugar, J., Charya, S., Johnson, G., Merril, C., Bierer, L., et al. (1991). Increased synthesis and accumulation of heat shock 70 proteins in Alzheimer's disease. Mol. Brain Res. 11, 249-254. doi: 10.1016/0169-328X(91)90033-T

Petrucelli, L., Dickson, D., Kehoe, K., Taylor, J., Snyder, H., Grover, A., et al. (2004). CHIP and Hsp70 regulate tau ubiquitination, degradation and aggregation. Hum. Mol. Genet. 13, 703-714. doi: 10.1093/hmg/ddh083

Querfurth, H. W., and LaFerla, F. M. (2010). Alzheimer's disease. N. Engl. J. Med. 362, 329-344. doi: 10.1056/NEJMra0909142

Reilly, C. E. (2001). Neprilysin content is reduced in Alzheimer brain areas. J. Neurol. 248, 159-160. doi: 10.1007/s004150170259

Reiman, E. M., Chen, K., Alexander, G. E., Caselli, R. J., Bandy, D., Osborne, D., et al. (2005). Correlations between apolipoprotein E epsilon4 gene dose and brain-imaging measurements of regional hypometabolism. Proc. Natl. Acad. Sci. U.S.A. 102, 8299-8302. doi: 10.1073/pnas.0500579102

Renkawek, K., Bosman, G. J., and Gaestel, M. (1993). Increased expression of heatshock protein $27 \mathrm{kDa}$ in Alzheimer disease: a preliminary study. Neuroreport 5 , 14-16. doi: 10.1097/00001756-199310000-00003

Ricci, E., Broccolini, A., Gidaro, T., Morosetti, R., Gliubizzi, C., Frusciante, R., et al. (2006). NCAM is hyposialylated in hereditary inclusion body myopathy due to GNE mutations. Neurology 66, 755-758. doi: 10.1212/01.wnl.0000200956. $76449.3 \mathrm{f}$ 
Ricotti, V., Roberts, R. G., and Muntoni, F. (2011). Dystrophin and the brain. Dev. Med. Child Neurol. 53, 12-12. doi: 10.1111/j.1469-8749.2010.03836.x

Roussel, B. D., Kruppa, A. J., Miranda, E., Crowther, D. C., Lomas, D. A., and Marciniak, S. J. (2013). Endoplasmic reticulum dysfunction in neurological disease. Lancet Neurol. 12, 105-118. doi: 10.1016/S1474-4422(12)70238-7

Rui, Y., Tiwari, P., Xie, Z., and Zheng, J. Q. (2006). Acute impairment of mitochondrial trafficking by beta-amyloid peptides in hippocampal neurons. J. Neurosci. 26, 10480-10487. doi: 10.1523/JNEUROSCI.3231-06.2006

Rust, M. B. (2015). ADF/cofilin: a crucial regulator of synapse physiology and behavior. Cell. Mol. Life Sci. 72, 3521-3529. doi: 10.1007/s00018-015-1941-z

Sabirzhanov, B., Stoica, B. A., Hanscom, M., Piao, C. S., and Faden, A. I. (2012). Over-expression of HSP70 attenuates caspase-dependent and caspaseindependent pathways and inhibits neuronal apoptosis. J. Neurochem. 123, 542-554. doi: 10.1111/j.1471-4159.2012.07927.x

Salama, M., Shalash, A., Magdy, A., Makar, M., Roushdy, T., Elbalkimy, M., et al. (2018). Tubulin and tau: possible targets for diagnosis of Parkinson's and Alzheimer's diseases. PLoS One 13:e0196436. doi: 10.1371/journal.pone. 0196436

Schedin-Weiss, S., Winblad, B., and Tjernberg, L. O. (2014). The role of protein glycosylation in Alzheimer disease. FEBS J. 281, 46-62. doi: 10.1111/febs.12590

Scheltens, P., Blennow, K., Breteler, M. M. B., de Strooper, B., Frisoni, G. B., Salloway, S., et al. (2016). Alzheimer's disease. Lancet 388, 505-517. doi: 10. 1016/S0140-6736(15)01124-1

Schenk, D., Basi, G. S., and Pangalos, M. N. (2012). Treatment strategies targeting amyloid $\beta$-protein. Cold Spring Harb. Perspect. Med. 2:a006387. doi: 10.1101/ cshperspect.a006387

Schnaar, R. L., Gerardy-Schahn, R., and Hildebrandt, H. (2014). Sialic acids in the brain: gangliosides and polysialic acid in nervous system development, stability, disease, and regeneration. Physiol. Rev. 94, 461-518. doi: 10.1152/ physrev.00033.2013

Sela, I., Krentsis, I. M., Shlomai, Z., Sadeh, M., Dabby, R., Argov, Z., et al. (2011). The proteomic profile of hereditary inclusion body myopathy. PLoS One 6:e16334. doi: 10.1371/journal.pone.0016334

Serrano-Pozo, A., Frosch, M. P., Masliah, E., and Hyman, B. T. (2011). Neuropathological alterations in Alzheimer disease. Cold Spring Harb. Perspect. Med. 1:a006189. doi: 10.1101/cshperspect.a006189

Sibille, E. (2013). Molecular aging of the brain, neuroplasticity, and vulnerability to depression and other brain-related disorders. Dialogues Clin. Neurosci. 15, 53-65.

Siddiqui, S. S., Springer, S. A., Verhagen, A., Sundaramurthy, V., Alisson-Silva, F., Jiang, W., et al. (2017). The Alzheimer's Disease-protective CD33 splice variant mediates adaptive loss of function via diversion to an intracellular pool. J. Biol. Chem. 292, 15312-15320. doi: 10.1074/jbc.M117.799346

Singh, R., and Arya, R. (2016). GNE Myopathy and cell apoptosis: a comparative mutation analysis. Mol. Neurobiol. 53, 3088-3101. doi: 10.1007/s12035-0159191-5

Singh, R., Chaudhary, P., and Arya, R. (2018). Role of IGF-1R in ameliorating apoptosis of GNE deficient cells. Sci. Rep. 8:7323. doi: 10.1038/s41598-01825510-9

Siparsky, P. N., Kirkendall, D. T., and Garrett, W. E. (2014). Muscle changes in aging: understanding sarcopenia. Sports Health 6, 36-40. doi: 10.1177/ 1941738113502296

Smith, M. H., Ploegh, H. L., and Weissman, J. S. (2011). Road to ruin: targeting proteins for degradation in the endoplasmic reticulum. Science 334, 1086-1090. doi: $10.1126 /$ science. 1209235

Son, S. M., Jung, E. S., Shin, H. J., Byun, J., and Mook-Jung, I. (2012). A $\beta$-induced formation of autophagosomes is mediated by RAGE-CaMKK $\beta$-AMPK signaling. Neurobiol. Aging 33:1006.e11-23. doi: 10.1016/j.neurobiolaging.2011. 09.039

Souchay, C., and Moulin, C. (2009). Memory and consciousness in Alzheimers disease. Curr. Alzheimer Res. 6, 186-195. doi: 10.2174/156720509788486545

Spiro, R. G. (2002). Protein glycosylation: nature, distribution, enzymatic formation, and disease implications of glycopeptide bonds. Glycobiology 12, 43R-56R. doi: 10.1093/glycob/12.4.43R

Stemmer, N., Strekalova, E., Djogo, N., Plöger, F., Loers, G., Lutz, D., et al. (2013). Generation of amyloid- $\beta$ is reduced by the interaction of calreticulin with amyloid precursor protein, presenilin and Nicastrin. PLoS One 8:e61299. doi: 10.1371/journal.pone.0061299
Stone, S., and Lin, W. (2015). The unfolded protein response in multiple sclerosis. Front. Neurosci. 9:264. doi: 10.3389/fnins.2015.00264

Supnet, C., and Bezprozvanny, I. (2010). Neuronal calcium signaling, mitochondrial dysfunction, and Alzheimer's disease. J. Alzheimers Dis. 20(Suppl. 2), S487-S498. doi: 10.3233/JAD-2010- 100306

Swerdlow, R. H. (2018). Mitochondria and mitochondrial cascades in Alzheimer's disease. J. Alzheimers Dis. 62, 1403-1416. doi: 10.3233/JAD-170585

Tabas, I., and Ron, D. (2011). Integrating the mechanisms of apoptosis induced by endoplasmic reticulum stress. Nat. Cell Biol. 13, 184-190. doi: 10.1038/ ncb0311-184

Taylor, J. P., Brown, R. H., and Cleveland, D. W. (2016). Decoding ALS: from genes to mechanism. Nature 539, 197-206. doi: 10.1038/nature20413

Thibault, O., Hadley, R., and Landfield, P. W. (2001). Elevated postsynaptic $[\mathrm{Ca} 2+] \mathrm{i}$ and L-type calcium channel activity in aged hippocampal neurons: relationship to impaired synaptic plasticity. J. Neurosci. 21, 9744-9756. doi: 10.1523/JNEUROSCI.21-24-09744.2001

Thibault, O., Porter, N. M., Chen, K. C., Blalock, E. M., Kaminker, P. G., Clodfelter, G. V., et al. (1998). Calcium dysregulation in neuronal aging and Alzheimer's disease: History and new directions. Cell Calcium 24, 417-433. doi: 10.1016/ S0143-4160(98)90064-1

Tung, Y. T., Wang, B. J., Hsu, W. M., Hu, M. K., Her, G. M., Huang, W. P., et al. (2014). Presenilin-1 regulates the expression of p62 to govern p62-dependent tau degradation. Mol. Neurobiol. 49, 10-27. doi: 10.1007/s12035-013-8482-y

Uddin, M. S., Stachowiak, A., Al Mamun, A., Tzvetkov, N. T., Takeda, S., Atanasov, A. G., et al. (2018). Autophagy and Alzheimer's disease: from molecular mechanisms to therapeutic implications. Front. Aging Neurosci. 10:04. doi: 10. 3389/fnagi.2018.00004

Wang, B. (2009). Sialic Aacid is an essential nutrient for brain development and cognition. Annu. Rev. Nutr. 29, 177-222. doi: 10.1146/annurev.nutr.28.061807. 155515

Wang, P.-L., Niidome, T., Akaike, A., Kihara, T., and Sugimoto, H. (2009). Rac1 inhibition negatively regulates transcriptional activity of the amyloid precursor protein gene. J. Neurosci. Res. 87, 2105-2114. doi: 10.1002/jnr.22039

Wang, X., and Michaelis, E. K. (2010). Selective neuronal vulnerability to oxidative stress in the brain. Front. Aging Neurosci. 2:12. doi: 10.3389/fnagi.2010.00012

Wang, Z., Sun, Z., Li, A. V., and Yarema, K. J. (2006). Roles for UDP-GlcNAc 2epimerase/ManNAc 6-kinase outside of sialic acid biosynthesis: modulation of sialyltransferase and BiP expression, GM3 and GD3 biosynthesis, proliferation, and apoptosis, and ERK1/2 phosphorylation. J. Biol. Chem. 281, 27016-27028. doi: $10.1074 /$ jbc.M604903200

Weidemann, W., Stelzl, U., Lisewski, U., Bork, K., Wanker, E. E., Hinderlich, S., et al. (2006). The collapsin response mediator protein 1 (CRMP-1) and the promyelocytic leukemia zinc finger protein (PLZF) bind to UDP-Nacetylglucosamine 2-epimerase/ $\mathrm{N}$-acetylmannosamine kinase (GNE), the key enzyme of sialic acid biosynthesis. FEBS Lett. 580, 6649-6654. doi: 10.1016/j. febslet.2006.11.015

Wischik, C. M., Harrington, C. R., and Storey, J. M. D. (2014). Tau-aggregation inhibitor therapy for Alzheimer's disease. Biochem. Pharmacol. 88, 529-539. doi: 10.1016/j.bcp.2013.12.008

Wiseman, F. K., Al-Janabi, T., Hardy, J., Karmiloff-Smith, A., Nizetic, D., Tybulewicz, V. L. J., et al. (2015). A genetic cause of Alzheimer disease: Mechanistic insights from Down syndrome. Nat. Rev. Neurosci. 16, 564-574. doi: $10.1038 / \mathrm{nrn} 3983$

Woodling, N. S., Colas, D., Wang, Q., Minhas, P., Panchal, M., Liang, X., et al. (2016). Cyclooxygenase inhibition targets neurons to prevent early behavioural decline in Alzheimer's disease model mice. Brain 139(Pt 7), 2063-2081. doi: 10.1093/brain/aww117

Xiang, C., Wang, Y., Zhang, H., and Han, F. (2017). The role of endoplasmic reticulum stress in neurodegenerative disease. Apoptosis 22, 1-26. doi: 10.1007/ s10495-016-1296-4

Xie, T., Yan, C., Zhou, R., Zhao, Y., Sun, L., Yang, G., et al. (2014). Crystal structure of the $\gamma$-secretase component nicastrin. Proc. Natl. Acad. Sci. U.S.A. 111, 13349-13354. doi: 10.1073/pnas.1414837111

Yan, C., Ikezoe, K., and Nonaka, I. (2001). Apoptotic muscle fiber degeneration in distal myopathy with rimmed vacuoles. Acta Neuropathol. 101, 9-16.

Yang, D.-S., Lee, J.-H., and Nixon, R. A. (2009). Monitoring autophagy in Alzheimer's disease and related neurodegenerative diseases. Methods Enzymol. 453, 111-144. doi: 10.1016/S0076-6879(08)04006-8 
Yang, D. S., Tandon, A., Chen, F., Yu, G., Yu, H., Arawaka, S., et al. (2002). Mature glycosylation and trafficking of nicastrin modulate its binding to presenilins. J. Biol. Chem. 277, 28135-28142. doi: 10.1074/jbc.M110871200

Yatin, S. M., Varadarajan, S., Link, C. D., and Butterfield, D. A. (1999). In vitro and in vivo oxidative stress associated with Alzheimer's amyloid beta-peptide (1-42). Neurobiol. Aging 20, 325-330.

Yonekawa, T., Malicdan, M. C. V., Cho, A., Hayashi, Y. K., Nonaka, I., Mine, T., et al. (2014). Sialyllactose ameliorates myopathic phenotypes in symptomatic GNE myopathy model mice. Brain 137, 2670-2679. doi: 10.1093/brain/awu210

Zare-Shahabadi, A., Masliah, E., Johnson, G. V. W., and Rezaei, N. (2015). Autophagy in Alzheimer's disease. Rev. Neurosci. 26, 385-395. doi: 10.1515/ revneuro-2014-0076

Zhang, W., Huang, Y., and Gunst, S. J. (2012). The small GTPase RhoA regulates the contraction of smooth muscle tissues by catalyzing the assembly of cytoskeletal signaling complexes at membrane adhesion sites. J. Biol. Chem. 287, 33996-34008. doi: 10.1074/jbc.M112.369603
Zhang, Y., Thompson, R., Zhang, H., and Xu, H. (2011). APP processing in Alzheimer's disease. Mol. Brain 4:3. doi: 10.1186/1756-6606-4-3

Zhao, Q. F., Yu, J. T., and Tan, L. (2014). S-Nitrosylation in Alzheimer's disease. Mol. Neurobiol. 51, 268-280. doi: 10.1007/s12035-014-8672-2

Conflict of Interest Statement: The authors declare that the research was conducted in the absence of any commercial or financial relationships that could be construed as a potential conflict of interest.

Copyright (C) 2018 Devi, Yadav, Chanana and Arya. This is an open-access article distributed under the terms of the Creative Commons Attribution License (CC BY).

The use, distribution or reproduction in other forums is permitted, provided the original author(s) and the copyright owner(s) are credited and that the original publication in this journal is cited, in accordance with accepted academic practice. No use, distribution or reproduction is permitted which does not comply with these terms. 